\section{INFECTIVE JAUNDICE.}

Șir BERTRAND DAWSON, K.O.V.O., C.B., M.D., B.Sc., F.R.C.P.,

Colonel A.M.s: Physician to H.M. the King; Congulting

PHYsictan, BRITISH EXPEDITIONARY ForCe; Prysician LONDON HOSPITAL:

W. E. HUME, M.A., M.D.Cantab., F.R.C.P.Lond., Liedt.-Colonel R.A.M.C.(T.F.);

AND

S. P. BEDSON, M.D., M.Sc., Captain R.A.M.C.

Historicai, Account.

EPIDEMICs of jaundice have been described from the earliest times, and many of the best accounts have been compiled from the study of the disease in armies in the field. Cockayne draws attention to the fact that the author-probably Hippocrates-of the De Internis Affec-

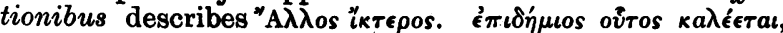

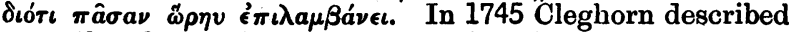
an outbreak of epidemic jaundice in Minorca, and Larrey, in 1800 , published an account of an epidemic of jaundice during the siege of Cairo, and drew particular attention to the contagiousness of the disease and to the occurrence of haemorrhages in his patients. Amongst French writers, Ozanam (1846-9), Monneret (1859), the elder Laveran (1865), Lancereaux (1882), Landouzy (1882), and Mathieu (1886), have all described epidemic diseases of varying intensity in which jantice was a constant feature. Lancereaux described hive cases under the title of "Ictère grave essentiel," and Landouzy called the disease "Fièrre bilieuse," and Mathieu, drawing attention to the frequent occurrence of relapses, gave to his description the title of "Ictère fébrile a rechutes." The accounts of the diseases described by these authors vary, and it is probable that there were different etiological factors in each epidemic.

Attention may be drawn, however, to certain descriptions in so far as they throw light upon the particular type of epidemic jaundice which is to be described in these pages. In 1859 Carville described an epidemic in the garrison at Gaillon, and gives an account of 47 cases, of whom 11 died. All developed jaundice, and albuminuria was present in every case. Haemorrhages were common; 15 had epistaxis, in 3 there was purpura, and in one haematemesis. The incubation period was six days. A similar epidemic was described by Worms in St. Cloud in May, 1865.

Mathieu in 1886 described cases of jaundice and drew attention to the fact that the term "catarrhal jaundice" was an insufficient description, and claimed that the fever, general symptoms, enlargement of the spleen and albuminuria, justified the title of infectious jaundice.

Weil in 1886, and some months after the publication of Mathieu's report, described four cases of infectious jaundice, and drew attention to the relapses of fever which occurred in two out of the four cases. From this time onwards the symptom-complex of fever, jaundice, enlargement of the liver and spleen, the occurrence of haemorrhages, and occasional febrile relapses, have been described under the name of Weil's disease. This last title has served the purpose of labelling with a simple name any disease which embraced the signs and symptoms which we have just enumerated. Both historically and scientifically the title is incorrect and vague. Epidemic jaundice was described by the Father of Medicine, and his disciples in later years have only added little by little to a clinical picture which is still far from being complete. There is no doubt that there are many and different etiological factors which can give rise to a clinical picture in which fever, jaundice, haemorrhages, enlargement of the liver and spleen, and relapses of fever are variously, but not constantly, present. In none of the descriptions quoted above is the picture complete. In none has the cause ever been proved, and in many it is not even suggested. I $\mathfrak{u}$ ing the last three years, however, we have been enabled to recognize a form of infectious jaundice in which the clinical and pathological picture is uniform and constant, and of which the cause has been discovered and proved.

In November, 1914, two Japanese workers, Inada and Ido, showed the presence of a spirochaete in the liver of a guinea-pig which had been inoculated with the blood of a patient suffering from a form of infectious jaundice. Some months later they proved the specificity of this spirochaete, and gave to it the name of Spirochaeta ictero. haemorrhagiae. In a later part of this paper the work of these Japanese authors is set forth in greater detail. In the British and French armies it has been shown-con. clusively that an infectious disease usually accompanied by jaundice is caused by the Spirochaeta icterohaemor rhagiae, and descriptions of the clinical and pathological findings have been published by Dawson and Hume, Stokes, Ryall, and others in the British army; and in the French army by Martin and Pettit, Garnier and Reilly, and Costa and Troisier.

Before describing this disease it may be recalled that jaundice has been a relatively common disorder in armies in the field. In the Federal troops in the war between North and South America there were 22,509 cases, with 161 deaths, amongst a total of $2,218,559$ men. In 1870 from February to May, there were 799 cases amongst 33,380 men in the Bavarian troops stationed to the south. west of Paris. During five months in the South African war there were 5,648 cases, with a small mortality.

Since the commencement of the present war we have been unable to ascertain the incidence of cases of jaundice amongst the British and French troops in France. Before we were in possession of the Japanese work we were able to prove that certain cases of jaundice belonged to the enteric group of diseases. In the summer and autumn of 1915 our attention was arrested by the occurrence of severe cases of jaundice in which there were high fever, haemor. rhages, enlargement of the liver, and a tendency to febrile relapses, which in no way conformed either clinically or bacteriologically to the typhoid group.

In the autumn of 1915 we made a special endeavour to study these cases by collecting them into a single hospital, and the result of our work has been published in detail in the Quarterly Journal of Medicine, October, 1916, and January, 1917. It was only in April and May, 1917, that we were able to show that the Spirochaeta icterohaemorrhagiae was the cause of this disease, after we had read the account of the Japanese work published in the Journal of Experimental Medicine.

Chinical Description of the Disease.

In order to draw attention to the characteristic features of this disease, a complete case will be briefly described and an account of the chief signs and symptoms will be set forth under the headings of the various systems of the body.

On August 7th, 1917, Pte. A. B. was suddenly seized with vomiting and diarrhoea, with a feeling of intense weakness. For two days he lay in. his billet with a temperature of $103^{\circ}$ to $104^{\circ}$ and had frequent diarrhoeal stools. On August 9th the prostration was very marked and there was a considerable amount of blood in the stools. The temperature was $101^{\circ}$. On August 12th he was noticed to be jaundiced. On August 14th he had an attack of haemoptysis and spat up about one pint of blood, and the expectoration was blood-stained for the following five days.

On admission to a base hospital on August 16th, there was universal intense jaundice and the temperature was $101.2^{\circ}$. There was a scabby mass of haemorrhagic herpes about the lips. The tongue was brown and very dry. The patient was drowsy and there was considerable abdominal distension and discomfort. The initial diarrhoea was followed by constipation, which necessitated the use of enemata. There was marked tenderness in the right hypochondrium and the liver was enlarged to three fingerbreadths below the right costal margin. The spleen was not palpable. The red blood cells numbered $4,800,000$ to the cubic millimetre and the haemoglobin was 80 per cent. . The white cells numbered 24,000 to the cubic milli. metre and a differential count showed :

$$
\begin{array}{lcccc}
\text { Polymorphonuclear leucocytes } & \ldots & \ldots & 82 \text { per cent. } \\
\text { Lymphocytes } \ldots & \ldots & 10 & , \\
\text { Large mononuclear leucocytes } & \ldots & \ldots & 5 & , \\
\text { Coarsely granular eosinophilè leucocytes } & . . & 3 & 3
\end{array}
$$

The urine was loaded with bile, and there was a sixth of a boiled test tube of albumin together with granular casts. Some bile was escaping into the duodenum as the stools were of a light brown colour.

There were crepitations to be heard over the lower lobes of the lungs. There was no recurrence of haemoptysis or melaena. During the first fortnight of the illness the patient complained much of pains in the back and

[2959] 
limbs. On August 20th the temperature had fallen to $98^{\circ}$ to $99^{\circ}$, though the jaundice was still intense. On August 26th the jaundice was rapidly fading, and on this day spirochaetes were found in the urine in large numbers. During the next five days the general condition of the patient improved so much that he was sent to England on August 31st. There was no secondary rise of fever while the patient was in France.

Such is the usual history of a case of moderate severity, and the noteworthy features are the following: A sudden onset with gastro-intestinal symptoms and high fever, the marked prostration, the occurrence of melaena and haemoptysis, the presence of haemorrhagic herpes, the appearance of jaundice on the fifth day, the fall of temperature at the end of eleven days, and the finding of typical spirochaetes in the urine.

\section{General Features of the Disease.}

The Onset.-The patient has almost invariably been attacked by the disease either in the trenches or immediately after having left them. The onset is usually sudden, with shivering, pains in the head and particularly behind the eyes, generalized pains, and a feeling of extreme prostration. So sudden is the onset that the pationt can frequently point to an exact moment when he finds himself overcome; as one said, he "fell out very weak" on the march; or in another instance, he "suddenly collapsed at church parade." At the time of reporting sick the temperature is raised to $103^{\circ}$ to $105^{\circ}$ and the pulse rate is about 100 per minute. During the first two or three days before the appearance of jaundice there are vomiting, great prostration and lassitude, with abdominal and muscular pains. The conjunctivae are injected, and herpes, which rapidly becomes haemorrhagic, appears on the lips.

Gastro-intestinal.-A dirty, brown tongue and anorexia is common to all; constipation is the rule, and it is only rarely that there is diarrhoea at the onset, as in the case described above. The constipation is usually extreme and has to be relieved by enemata. The stools may become clay-coloured, though in most cases the presence of a small quantity of bile gives the stool a light-brown coloration. Usually there is considerable abdominal tenderness, which is more marked in the upper than in the lower abdomen. Though vomiting is usual at the onset, it generally ceases before the patient reaches a base hospital, on the sixth to eighth day of the disease. Hiccough was occasionally present in very severe or fatal cases. Melaena sometimes occurred in patients with diarrhoea.

The liver is frequently enlarged to the extent of three finger's' to a hand's breadth below the right costal margin and the tissues covering it are usually very sensitive and tender.

The spleen has only been palpable on two occasions in our experience. From observation at operation and from the size of the organ at post-mortem examination it seems certain that the spleen is very rarely sufficiently enlarged to be palpable.

The superficial lymphatic glands are frequently palpable in the axillae and groins.

Haemorrhages.-Out of eighteen severe cases under our care, fourteen had haemorrhages. Haematemesis occurred in four and haemoptysis in six. Epistaxis was considerable in four cases and slight in two cases. Melaena was observed in three instances and in three there was a marked purpuric eruption in the skin. In one patient there were epistaxis, haemoptysis, and melaena.

The Skin.-The jaundice usually appears about the fourth day of disease and gradually deepens up to the eighth or ninth day and then fades. In some cases it is very intense and the skin takes the greenish hue met with in complete obstruction of the common bile duct. Herpes labialis, which is haemorrhagic, occurs in at least 40 per cent. of all cases. Pruritus is rarely intense, though patients frequently complain of some itching of the skin. The conjunctivae are often injected and the eyeballs are tender.

The Circulatory System.-The rate of the heart does not increase in proportion to the rise of temperature, and in severe cases with a temperature of $104^{\circ}$ to $105^{\circ}$ the pulse-rate may be only 100 per minute. The rhythm of the heart is not usually affected, except in one patient, in whom auricular fibrillation, of which records were obtained, persisted for five days. The size and sounds of the heart are perfectly normal. The blood pressure never falls as it does in the enteric group of diseases, and the systolic pressure ranges about $120 \mathrm{~mm}$. of mercury. The qualitative changes in the peripheral blood will be described in the section on clinical pathology.

T'he Respiratory System. - In all severe cases there are the evidences of an acute bronchitis, but we have never discovered any signs pointing to bronchopneumonia or lobar pneumonia. Reference has already been made to the occurrence of haemoptysis and rusty sputum. The respiratory rate may be increased to 28 or 30 per minute in severe cases, and in fatal cases the type of breathing is that met with in cases of cholaemia and uraemia.

The Nervous System.-Frontal headache and aching belind the eyeballs is a constant complaint, and is liftle relieved by antipyretics. The early weakness and prost.a. tion are very characteristic of this disease. In our f cases twitchings and convulsions preceded the comd in which the patients died. In many cases the muscular pains are very intense, and the whole body is so sensitive that the patient cannot bear any pressure upon it. One patient complained of xanthopsia.

The Urinary System.-Three of our patients had retention of urine, which required the use of the catheter for two or three days. The cause of this disability probably lay in the central nervous system. The urine usually contains a large quantity of bile, which sometimes gives it a dark porter colour. The bile does not usually disappear from the urine till the end of the fourth or fifth week. Albumin can nearly always be detected by the boiling method. In more severe cases, after heating in a tesi tube and allowing it to stand for twenty. four hours, the albuminons deposit amounts to one-sixth of the boiled test tube. Casts, hyaline and granular, are frequently found without centrifugalization, and at times free blood cells are seen in the deposit. The presence of reducing sugar was never detected, though acetone is said by others to occur in cholaemic cases, probably the result of starvation. The chemistry of the urine has been fully worked out in this disease by certain French authors, who lay considerable stress on the evidences of renal insufficiency.

The Fever.-The initial rise of temperature to $103^{\circ}$ or $105^{\circ}$ has already been noted, and during the first twelve or fourteen days there is an irregular range of temperature between $100^{\circ}$ and $103^{\circ}$, which gradually falls by lysis to normal or subnormal. After the fall the temperature may be subnormal for two to three days. After this, in sou cases about the beginning of the third week, there is a secondary rise of temperature, which lasts for ten to fifteen days. During this period of secondary fever there are usually no évidences of exacerbation of symptoms, and it is difficult to account for its occurrence. In those cases in whom there is no secondary fever the temperature

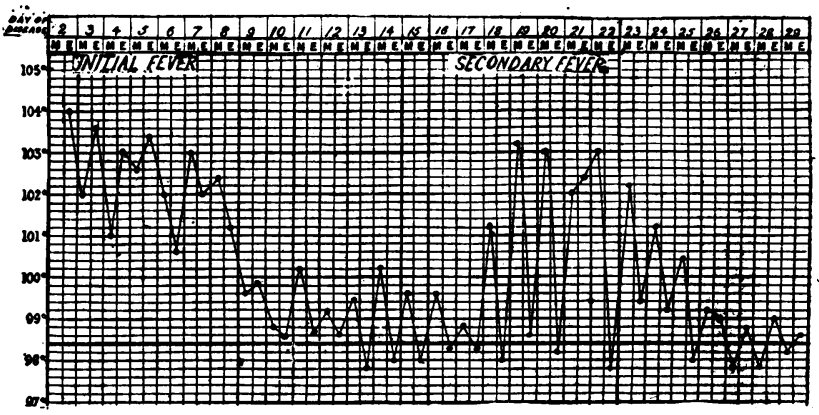

Chart I.

may swing about $99^{\circ}$ for a week or more before finally settling to the normal. Chart 1 shows a characteristic fever of relapse.

Course of the Disease. - The first three or four days have been described in the section on the onset of the disease. The jaundice, which has appeared about the fourth day, gradually increases, and is most intense about the tenth to twelfth day. It is then that the temperature falls to normal. In uncomplicated cases the patient begins to improve and the jaundice begins to disappear at the end of the second week. Between the third and fourth weeks 


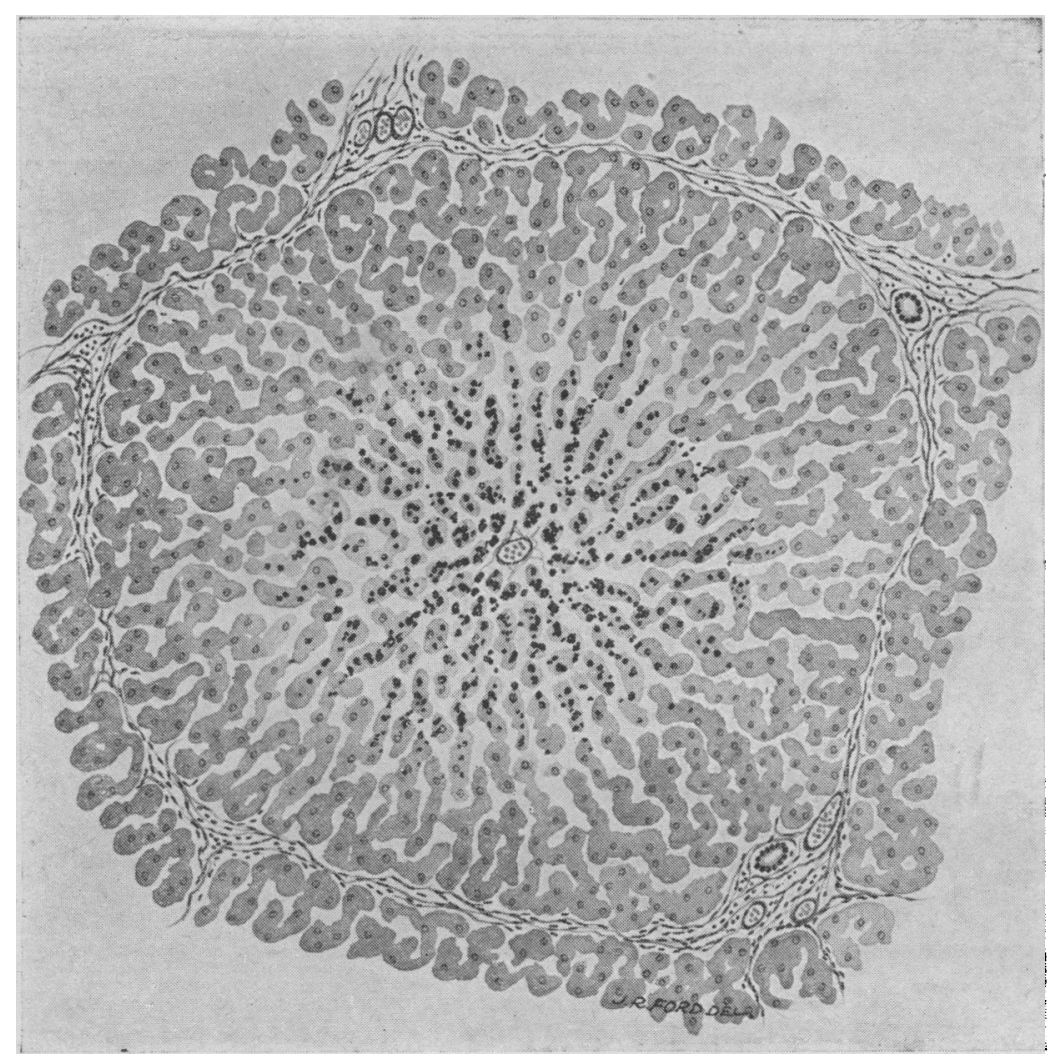

FIG. 1.-Section of liver from a case of sprrocnaetal jaundice. The liver cells and their arrangement appear normal. It shows biliary stasis and collections of cells in the portal areas.

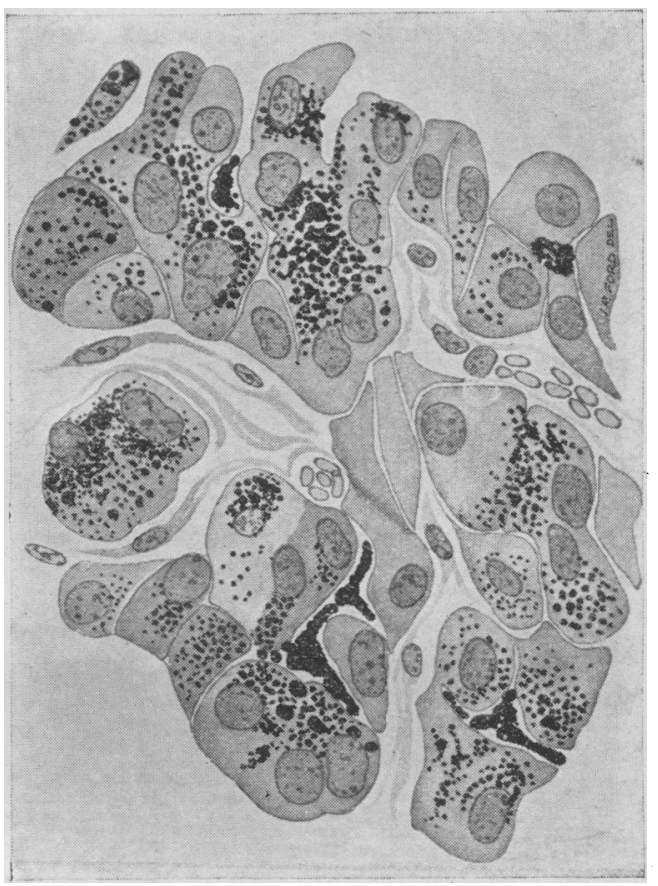

FIG. 2.-Section from the same liver as Fig. 1. (High power.)

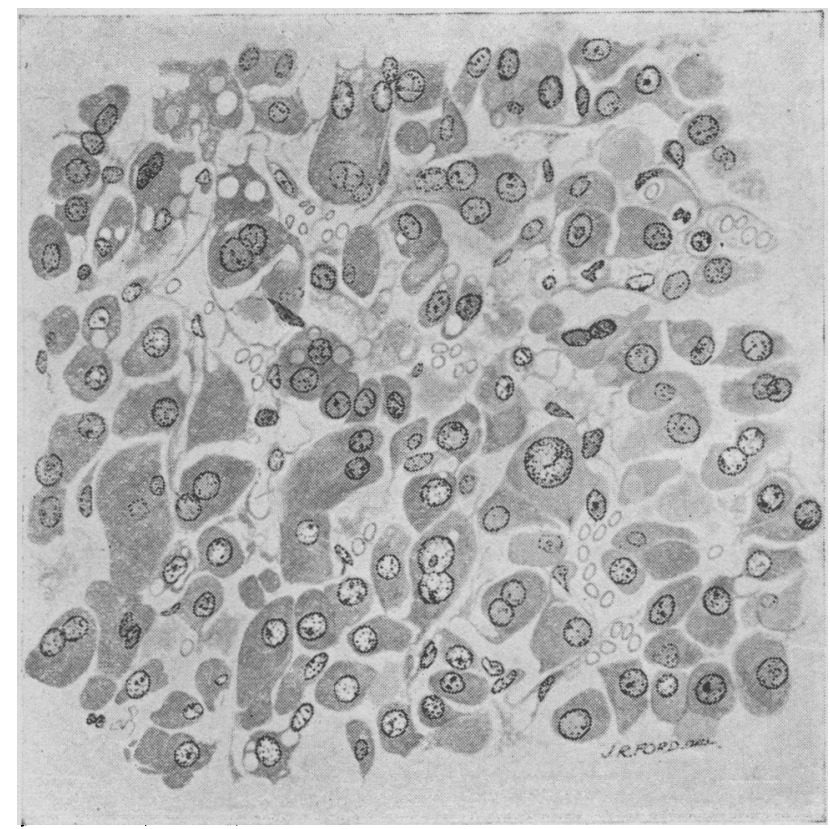

FIG. 3.-Spirochaetes in the blood of a guinea-pig experimentally infected.

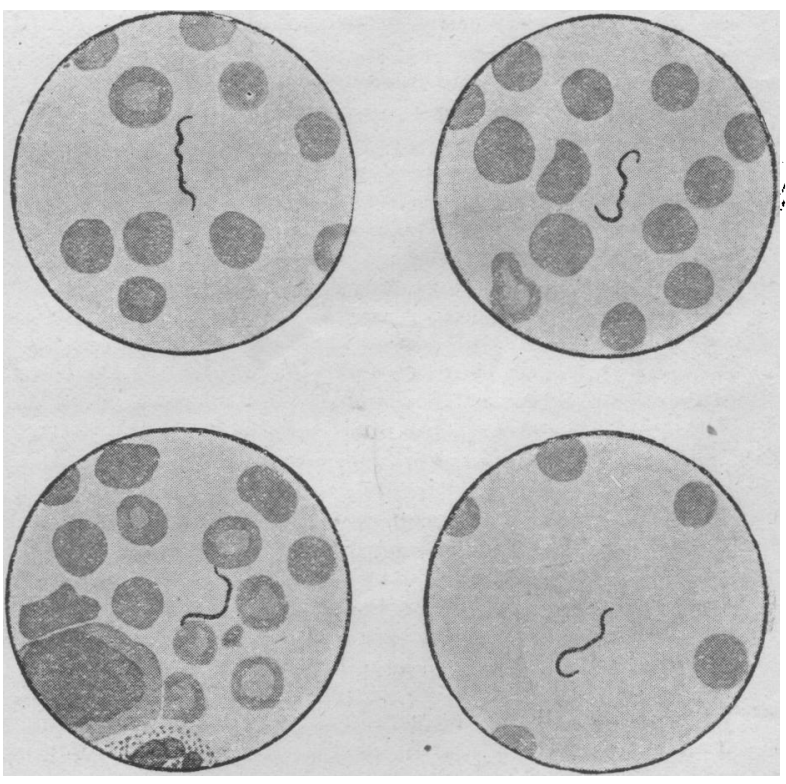
FiG. 4.-Section of liver from a case of spirochaetal jaundice.
Showing dissociátion of cells. 
convalescence has become established. The whole disease is more protracted in severe cases, and convalescence may not begin until the end of the fourth week. As far as we know, the disease leaves behind it no untoward symptoms.

The following is an account of a fatal case:

Pte. C. D. was taken ill with a sudden chill and shiver. ing on December 16th. He had to take to his bed, and complained of headache, nausea, and pains in both thighs. $\mathrm{He}$ frequently felt chilly and had pain in the epigastrium. On December 21st he became jaundiced. On this day no abnormal physical signs could be detected in any of the systems, except some epigastric tenderness, jaundice, and a haemorrhagic herpetic eruption on the lips. Vomiting had been occasional from the onset of the illness, and at the end of the first week nothing could be retained in the stomach. After the seventh day the jaundice steadily deepened and the urine was loaded with bile and contained one-sixth of a boiled test tube of albumin. The stools were liquid and of a pale yellow colour.

Except on the first day of admission to a base hospital (fourth day of disease), when the temperature was $101^{\circ}$, there was no pyrexia, and both the pulse and respiration rates fell, to 60 and 16 respectively. There was considerable tenderness of the upper abdomen and the muscles were slightly rigid. The liver was enlarged and the edge extended three fingerbreadths below the costal margin. The spleen was not palpable. An examination of the blood showed 34,100 white cells per cubic millimetre, and the differential count was :

$$
\begin{aligned}
& \text { Polymorphonuclear leucocytes ... } 93 \text { per cent. } \\
& \text { Lymphocytes } \ldots \text {. }
\end{aligned}
$$

A culture made from the urine was sterile. The faeces showed some blood, but no parasites, no ova, and no organisms of the enteric group were detected.

In the forenoon of December 29th some twitching of the face and arms was noticed, and about an hour later the patient had a general tonic, followed by a clonic, convulsion. The patient died one hour after this convulsion. The most noteworthy lesions at the post-mortem examination were subendocardial, subpleural, and subperitoneal haemorrhages and large extravasations of blood into both lungs, like infarcts.

Prognosis.

Most cases recover fully, and we would estimate that the mortality is not more than .4 to 5 per cent.

\section{Treatment.}

Thus far the treatment has been purely symptomatic. During the febrile period the patient is encouraged to drink large quantities of fluid, and an alkaline mixture is usually exhibited. Constipation is combated either by saline purges or by enemata. Salvarsan has been tried but it is of no avail. We believe that the serum of convalescent patients has been injected into the blood stream of severe cases, but the results of this method of treatment are not in our possession. An antiserum has been prepared and is available for use in the army.

\section{Differential Diagnosis.}

The rôle of the Spirochaeta icterohaemorrhagiae in this disease is discussed at some length, and the proof that it is the causal agent is established in a later part of this paper. We may anticipate by here stating (1) that the spirochaete may be found in the human peripheral blood stream (2) that injection of infected human blood into the peritoneal cavity of the guinea.pig may produce a characteristic fatal illness in that animal, in whose tissues post mortem the spirochaetes are present in large numbers; (3) that after the first fortnight of the disease the spirochaete may be found in the patient's urine.

In the early stages of this disease the most rapid and the most certain criterion in diagnosis lies in the discovery of the spirochaete in the peripheral blood stream. As the incubation period of the disease in the guinea-pig is at least six days, it would require a wait of at least eight days before the development of the disease in the guineapig could establish the diagnosis. After the second week of illness the discovery of the spirochaete in the urine is sufficient evidence of the disease. These various criteria presuppose the employment of complete bacteriological equipment in the hands of experienced observers. These are not always at hand, and reliance has to be placed on the correct interpretation of the clinical signs and symptoms. The sudden onset with headache, generalized pains, and a sense of utter exhaustion, vomiting, conjunctival congestion, herpes labialis, and a temperature of $103^{\circ}$ to $104^{\circ}$, with jaundice appearing on the fourth or fifth day, make the diagnosis of spirochaetosis icterohaemorrhagica almost certain.

In France the chief causes of jaundice have been the Spirochaeta icterohaemorrhagiae, and members of the enteric group of organisms. Jaundice in typhoid or paratyphoid fever usually appears about the end of the second week. There are cases, however, of paratyphoid fever in which the jaundice appears as early as it does in spiro. chaetosis icterohaemorrhagica. The difficulty in diagnosis is then considerable. At the end of the first week help can be obtained in differentiating the two diseases by means of the atropine test. This test was introduced in the diagnosis of typhoid fever by Captain H. F. Marris, R.A.M.C. One-thirtieth of a grain of atropine sulphate is administered hypodermically, and the increase of pulse rate is recorded every minute for the following hour. If the rate of the heart only increases by ten beats or less, this is evidence that the patient is suffering from typhoid or paratyphoid fever. It is important to bear in mind that the rate of the heart before the injection must not be above 80 to 85 per minute. If the rate increases from 100 to 110 or 115 after the injection of atropine sulphate it is impossible to be certain whether the escape of 10 to 15 beats indicates a positive or negative result. It is rare that the organism can be isolated from the blood in the prevailing enteric group of diseases. In inoculated patients it is necessary to trace the agglutination curve from three to four readings. This means a delay of at least fourteen days after the first sample of blood has been taken.

Apart from these specific methods of differential diagnosis or the presence of a typical clinical picture there can be mere speculation.

Spirochaetal Infection without Jaundice.

It is almost certain that many cases of "P.U.O." in France have been due to the Spirochaeta icterohaemor. rhagiae, and in the absence of jaundice the difficulty in diagnosis may be great. It is becoming more generally recognized that this same spirochaete may give rise to a clinical picture in which there is an absence of jaundice. The following case illustrates this point.

Sudden onset with body pains, frontal headache, photo. phobia, and vomiting. Temperature on the first day $104^{\circ}$ pulse 100, and the patient was very ill. The conjunctivae were injected; herpes labialis was present, the spleen was not palpable; the urine showed on heating a thick cloud of albumin, but no bile. Bilious vomiting was persistent for several days.

By the fourteenth day the patient appeared convalescent, but on the twentieth day there was a return of fever and pains, which lasted for five days. After this recovery was slow, but continuous. Nine weeks after the onset spirochaetes were still present in the urine, though health was nearly re-established. At no time was there jaundice or bile pigment in the urine.

On the third day of illness $2 \frac{1}{2}$ c.cm. of the patient's blood were injected into the peritoneal cavity of a guinea. pig, which subsequently developed jaundice, and after death spirochaetes were to be seen in the sections of its liver.

For most of this record we are indebted to Captain $\mathrm{H}$. Carson, R.A.M.C.

Costa and Troisier have shown that in certain cases which present meningeal symptoms the cerebro-spinal fluid produces the characteristic disease in the guinea-pig. It is therefore necessary to bear this fact in mind in the elucidation of any case of fever presenting pronounced meningeal signs and symptoms.

It is unnecessary to pursue the differentiation of this disease with jaundice from the common affections of the biliary system associated with jaundice. Nor is it necessary to mention the various febrile diseases which might be confused with spirochaetosis icterohaemorrhagica before the development of jaundice, or with that type of the infection in which jaundice is altogether absent.

Cuinical Pathology.

Apart from the finding of the spirochaete in tho blood stream and the injection of infected blood into the guinea-pig, which are discussed below, examination of the 
peripheral blood reveals the following departures from the normal state. In all severe cases there is a slight anaemia, the average red coll count being 4 to $4 \frac{1}{2}$ million per c.mm., and the haemoglobin percentage is reduced to 80 to 90 per cent. Some cases become very anaemic, and in one case the red cells numbered $2 \frac{1}{2}$ million per c.mm. There is invariably a leucocytosis, amounting in some cases to 25,000 per c.mm. Differential counts show a relative increase of the polymorphonuclear leucocytes to 75 to 80 per cent.

'The fragility of the red cells has been frequently tested and is found to be either normal or slightly diminished. No abnormal red cells have ever been detected. It is certain, therefore, that the jaundice is not of haemolytic origin.

As there was evidence that the jaundice was due to some obstruction in the biliary passages, and as the postmortem cxamiuation on two cases suggested an inflammation of the duodenum, attempts were made on many occasions to siphon off the duodenal contents by means of an Einhorn tube. Though no spirochaete was ever detected in the fluid so obtained, the finding of catarrhal cells in large numbers suggested the presence of a duodenitis in some cases.

Many of our cases in whom the spiròchaete was discovered were investigated thoroughly from the point of view of the enteric group. The examinations were always negative, both from blood culture and from a study of the agglutination curve.

Morbid Anatomy.

The opportunities of post-nortem examination have - been few, and the following account is based on four cases in our own series and the accounts of four post-mortem examinations described by Captain Stokes and others. Six patients died on the ninth, twelfth, thirteenth, fourteenth, seventeenth, and twenty-eighth days respectively, and one patient, in whom the date of onset was doubtful, died on the fourth day after admission to a casualty clearing station.

All the bodies were deeply jaundiced with the exception of the case who had died on the twenty-eighth day.

The Stomach and Intestines.-As the jaundice in these cases appeared to be of the obstructive type, special attention was given to the condition of the duodenum, and in three of our cases the appearances pointed to a duodenitis. The mucous membrane was of a bluish-red colour, and the Brunner's glands appeared through the mucous membrane as small yellow, opaque areas, from the size of a pinhead to that of a split pea. The whole of the mucous mem. brane had a swollen, watery appearance. In these cases the area round the ampulla of Vater seemed to be particularly affected. Other cases did not show this same duodenal condition, and microscopic examination did not give any evidence of recent or old inflammation.

In one case there was a considerable submucous haemorrhage in the stomach, and in another a polypoid condition of the mucous membrane at the pyloric end. Scattered subperitoneal haemorrhages were commonly found over the small intestine. No noteworthy lesions were discovered in the mucous membrane of the small or large intestine in any other case. 'The omental glands were usually enlarged.

The Liver and Bile Passages.-Particular attention has been given to the naked eye and microscopic appearances of the larger bile passages. These were normal in appearance and showed no evidence of inflammation except in the last half-inch of the common duct lying within the duodenal wall. This was swollen and of bluish colour in resemblance to the duodenal mucous membrane. In one instance a probe passed along the common duct into the duodenum dislodged a formed plug which was impacted in the ampulla. A film made from this plug showed numerous epithelial cell nuclei embedded in a matrix of mucin.

In all cases the liver to the naked eye was normal in pattern and texture, though sometimes altered in colour, due to bile stasis. Microscopically its appearances varied. In one group the cells of the lobules were natural in arrangement and appearance, and, apart from evidence of biliary stasis, the only abnormal feature was the presence of collections of cells in the portal areas, such as occur in other diseases. (Figs. 1 and 2.) In another group the liver cells were dissociated (Fig. 4), and many were markedly enlarged and contained well-stained nuclei. Collections of such hypertrophied cells, with clear pale protoplasm, appeared, especially just beneath the capsule. Many liver cells contained two nuclei, and mitoses were numerous. Staining with Sudan III showed a very little fat, in the form of fine droplets, which wcre partly within the endothelium (Kupffer's cells).

The sum of these changes suggests the effect of damage which has been insufficient to cause extensive necrosis, but has acted as a stimulant to cell growtl. In addition, the portal areas show collections of small mononuclear cells and polymorphs, and towards the centres of the lobules both intracellular and extracellular granules and masses of pigment were found. These microscopic changes resemble those described by Beitzke and Herxheimer.

In one case there were only slight changes-namely, variations in the sizes of the nuclei, a few mitoses, vacuolation of the central cells of the lobules, and in one place a hepatic venule was fl'ed with a mass of dissociated liver cells mingled with red blood corpuscles. A film made from a scraping of this liver showed one characteristic spirochaete. Stokes in two cases describes an exudation of cells into the interstitial tissue surrounding the smaller bile ducts. He detected leucocytes lying "between tho liver columns, and usually between the vessels."

The Kidneys.-Stokes described the lesions in the kidneys under three headings: (1) Swelling and granular degeneration of the tubular epithelium, particularly of the proximal convoluted tubules and the ascending loops of Henle; (2) an exudation of polymorphonuclear leucocytes between the tubules and, more rarely, within them; (3) haemorrhages into the lumen of the tubules in poorly defined patches.

The glomeruli showed no changes in particular.

The Spleen.-In no case was there any enlargement or any sign of involvement of this organ. This harmonizes with the clinical observation that the spleen is not usually enlarged in this disease.

The pancreas was firm and to naked eye and microscopio examination was perfectly normal.

The Lungs. - In all our cases there were haemorrhages in the lungs, in two cases reaching the size and consistence which is met with in cases of mitral stenosis. There was nothing noteworthy in any of the other organs of the body. Stokes showed the presence of the spirochaete in the kidney in one of his cases. In no other morbid human tissue has he or have we been able to detect it.

\section{EXPERIMENTAL PATHOLOGY.}

\section{Historical.}

It is to the Japanese workers Inada and Ido that we owe the discovery of the Spirochaeta icterohaemorrhagiac. In November, 1914, they announced the discovery of a spirochaete in the liver of a guinea-pig which had developed jaundice and died as the result of the inoculation of blood from a case of jaundice, epidemics of which they were investigating in conjunction with Hoki, Kaneko, lto, and Matsuzali. This finding they weie able to repeat, the spirochacte being found in the liver and blood of the infected animals in large numbers. The infection was shown to be transmissible from animal to animal. Later these Japanese worker's were able to demonstrate the specificity of this spirochaete, the finding of it in the patient's blood in six cases, in the tissues in two fatal cases, and the discovery of protective substances against it in the serum of patients recovering from the disease putting this question beyond doubt. Similar findings were announced by the German workers Hübener and Reiter, Uhlenhuth and Fromme, and Bietzke, obtained by them during investigations of the jaundice epidemic amongst their troops. No mention, however, is made by them of the Japanese work. The reseai'ches of Stokes, Ryle and Tytler, Dawson and Hume, on the British front, and later those of Martin and Pettit, Garnier and Reilly, Costa and Troisier in the French army, have shown that a similar type of jaundice is epidemic on the Western front, findings corresponding with those of the Japanese having been obtained.

\section{II, Experimental Inoculation.}

Attempts to reproduce this condition in animals have shown that the guinea-pig is the animal of choice, the monkey and rabbit being more or less immune, whilst the 
mouse and white rat occupy an intermediate position The guinea pig can be infected by the intraperitoneal injection of the patient's blood or urine. In the case of blood, success can only be looked for with any degreo of certainty if it is taken early in the disease-fourth or fifth day-and though the blood $x$ say still be infective as late as the seventh, eighth, or ninth day, later than that period the results are almost always negative. The intraperitoneal injection of 3 to $5 \mathrm{c.cm}$. of blood gives the most satisfactory results. As regards the infectivity of the urine for the guinea-pig, some difference of opinion seems to exist. The Japanese authors claim that the patient's urine is infectious for the animal early in the disease, and as in the case of the blood, this diminishes as the disease progresses. They have, however, had positive results as late as the twenty.first day. On the other hand, Garnier and Reilly claim that it is only from the tenth to eleventh day onwards that the urine is capable of infecting the guinea-pig, that is to say, from the time the spirochaete can first be demonstrated in the urine microscopically, and that earlier in the disease the results of their experiments have been consistently negative. Stokes's attempts in this direction were on no single occasion attended with success, despite the fact that the centrifugalized deposit from large quantities of urine was employed and the attempts were -made at various periods of the disease. Our experiments, though few in number, were negative.

\section{The Disease in the Guinea-pig.}

The disease in the guinea-pig is characterized by jaundice, haemorrhages, conjunctival congestion, albuminuria, and pyrexia. It is nearly always fatal. The incubation period in the animals injected with the patient's blood is somewhat variable-from six to thirteen days. Stokes quotes a case in which it would appear to have been as long as eighty-six days. After several passages of a strain the incubation period is gradually reduced until it reaches a point where it remains more or less constant, between four and five days. The mode of inoculation naturally affects the incubation period, it being longe when the infectious material is injected subcutaneously. The disease is ushered in by a sharp rise in temperature the animal is quiet and refuses to eat. A temperature of $103^{\circ} \mathrm{F}$. is the rule, though it may rise to as much as $106^{\circ} \mathrm{F}$. Jaundice appears when the temperature has reached its maximum, the animal becomes more acutely ill, and usually twenty-four hours after its appearance we have a fall of temperature to subnormal, collapse, and death. Spirochaetes appear in the blood with the onset of pyrexia (Fig. 3), and can be demonstrated in the urine ante mortem. Conjunctival congestion is usually present, skin haenrorrhages and haematuria are not intrequent.

Blood Changes in the Guinea-pig.

Anaemia towards the end of the disease in the animal, according to Stokes, is marked and accompanied by a fall in the leucocyte count. Our observations, though few in number, do not bear out this statement, a moderate degree of anaemia only, and a polymorphonuclear leucocytosis with a total white count of from 18,000 to 25,000 being noticed. These findings bear out those of Dawson and Hume in this disease in man, a moderate polymorphonuclear leucocytosis being a constant feature. Apart from a certain degree of polychromasia, we have not found any changes on the part of the red cells.

Pathological Changes in the Guinea-pig.

The findings in guinea-pigs which have died of the disease, or which have been killed after the appearance of the jaundice, are characteristic. We have jaundice of varying intensity of the skin and all internal surfaces. As a rule the jaundice is marked, but occasionally, as in man, one meets with cases which show little or none. This is, however, a rare occurrence. Fine petechial haemorrhages are seen in the skin, subperitoneally and in the muscles, particularly those of the thighs and abdominal walls. The loose areolar tissue of the groins, axillae, and cervical regions shows haemorrhages of varying size, and the lymph glands in these regions are enlarged and frequently haemorrhagic. The post-peritoneal tissue also shows numerous haemorrhages, particularly in the region of the kidney, that organ being frequently surrounded by a layer of free blood. The small bowel is usually congested, and in the larger percentage of cases shows numerous sub. serous haemorrhages usually elliptical in share. On opening the gut it is occasionally noticed that the duodenum, particularly in its upper portions, is more congested and the mucosa more swollen than the rest of the small intestine. This same fact was drawn attention to by Dawson and Hume. The large bowel may show listle or nothing, or it may be the site of areas of haemorrhage, which vary from clusters of pin-point haemor.' rhages to areas 0.5 to $1 \mathrm{~cm}$. in diameter, which suggest the commencement of ulcer formation.

The kidneys are acutely congested and show minute haemorrhages, subcapsular and throughout the cortex. The suprarenals are usually the site of large haemor. rhages, as is the case in any acute toxaemia in the guineapig. The liver, as a rule, shows no macroscopic changes. The spleen is congested, friable, and in the majority of our cases showed distinct enlargement, though Stokes describes it as " not obviously enlarged." The epididymis and testicle may also show haemorrhages. The lungs show the most characteristic changes in the shape of multiple clear-cut haemorrhages, varying in size from that of a pinhead to a threepenny-piece, and giving rise to that appearance which the Japanese authors very happily describe as being like "the wings of a mottled buttertly." As pointed out by Stokes, the larger haenorrhages are usually confined to the lower lobes and may be arranged symmetrically along the lateral margins of them. Ho also draws attention to the fact that these haemorrhages in the lungs and intestine are of early appearance, having been noticed by him in animals killed twenty-four hours after injection. The heart, as a rule, shows nothing, but, as in the case of other viscera, it is sometimes the site of small haemorrhages.

\section{Pathological Histology.}

Liver.-The changes seen in the liver may vary fiom cloudy swelling to acute parenchymatous degeneration, small prescribed areas of cell necrosis sometimes being found on section. According to the Japanese, the biliary ducts show no congestion, but Stokes describes an inflam. matory process about the smaller bile ducts with a leaco. cytic infiltration of the affected areas - a pericholangitisand to this he is inclined to attribute the jaundice.

Kidney.-This organ shows those changes characteristic of an acute parenchymatous nephritis. The tubular epithelium shows degenerative changes, in many cases both marked and extensive. There is a leucocytic infiltration of varying degree around the affected tubules, and not infrequently the affected tubules in places are packed with leucocytes. Haemorrhages occur throughout the cortex and many tubules are seen to be filled with red cells. These degenerative processes fall chiefly on the proximal convoluted tubules and the thicker portion of the loop of Henle, the glomeruli as a rule not being markedly affected.

Suprarenals. - Almost invariably these organs are haemorrhagic, and in acute cases they show haemor. rhages involving practically the whole of their structure. The haemorrhages apparently originate in the medulla.

Lymphoid Tissue. - The spleen, lymph nodes, and Peyer's patches all show congestion and some endothelial proliferation. The spleen shows evidence of increased blood destruction, the sinuses being packed with macrophages containing red cells; free pigment and leucocytes are also present. The lymph glands occasionally show haemorrhage, and the Peyer's patches are usually surrounded by haemorrhage in the form of a thin layer of free blood, and also show extravasated blood throughout the lymphoid tissue.

Lung8. - The haemorrhages in the lungs are seen to be pyramidal in shape, with their base lying against the pleura. They are frequently limited by the boundaries of the lobule. The vessels leading to these areas of haemorrhage are frequently seen to be. packed with leucocytes, and Stokes describes cases in which thrombi have been noticed in these ressels, though he does not consider the evidence sufficient to attribute the haemorrhages to these thrombi.

Distribution of the Spirochaete in the Guinea-pig.-The spirochaete lives and multiplies in the blood stream and in various organs. It is usually extracellular, and when 
present in the tissues it is found in the interstitial tissue, or more rarely in the endothelium or in the phagocytic cells. In the guinea-pig, unlike the case in man, it is found with ease in the blood of the jaundiced animal, especially in the case of a strain which has gone through several animal passages and kills the animal rapidly. The liver contains the spirochaete in great numbers, and it is sufficient to make a smear from a portion of this organ to have a preparation showing a dozen or more spirochaetes per oil-immersion field. In stained sections the spirochaetes are seen to be numerous and extracellular for the most part, forming when very numerous a sort of garland round the individual cells. After the liver, the kidneys and suprarenals contain the largest number of spiro. chaetes. In the kidney they occur in the interstitial tissue between the tubules and also in the walls and lumen of the tubules themselves. Unlike the case in the liver, their distribution in the kidney is by no means general but is limited to areas, where, however, they are numerous. Although comparatively numerous in the blood stream, the spleen and bone marrow contain few. The lymphoid tissue (splenic follicles and lymph glands) also shows but few spirochaetes, and in the lungs, heart muscle, striated muscle and arterial walls they are rare. They are numerous in the urine from the commencement of the jaundice. Though the foregoing description of the distribution of the spirochaete in the diseased guinea-pig is true for the majority of cases, one occasionally meets with animals in which the spirochaete is only found with difficulty. It may be stated as a general rule, however, that those animals showing the most marked lesions contain the most spirochaetes.

Mode of Excretion.-In the guinea-pig the spirochaete is excreted in the bile, faeces, and urine, though it is only in the latter that it is with any ease demonstrated microscopically. The Japanese workers have shown, however, that all three are infective for the guinea-pig, their experiments with the bile of infected animals giving a greater percentage of successful results than those with the faeces and urine, despite the fact that on no single occasion were they able to demonstrate the spirochaete microscopically in it.

Technique of Transfer.-The disease can be transmitted from animal to animal most surely by employing the heart blood or the emulsion of liver of a diseased animal. Inada states that he found the former, injected in quantities of $2 \mathrm{c.cm}$., the most satisfactory, but our findings and those of Stolses would point to the emulsion of liver being the more certain of the two. In the case of the heart blood all that is necessary is to collect the blood with the usual precautions as regards sterility and to inject it intraperitoneally into the fresh guinea-pig. If the liver emulsion is to be employed, the liver is removed as rapidly as possible after opening the animal, using the greatest possible care to avoid contamination and is placed in a sterile vessel, where it is roughly ground up with a small quantity of normal saline. The resulting emulsion is then rapidly centrifuged to throw down the lumps of liver tissue, which would block the needle, and the fluid so obtained injected intraperitoneally or subcutaneously. The employment of a large-bored needle will be found advisable, and in all cases where a possible contamination is suspected, such as invasion of the liver tissue by bacteria post mortem should the animal have been dead some little time, the subcutaneous route for inoculation is the one of choice. In a like manner an emulsion of any other organ containing the spirochaete, such as the kidney or suprarenal, could be employed. Besides thre subcutaneous and intraperitoneal methods of inoculation which are employed as a rule owing to their simplicity, the guinea-pig can be infected by way of the mouth, feeding the animal on food soaked in liver emulsion, by applying the virus to one of the available mucous surfaces, and by smearing it on to the shaved skin.

III. MoRPhOLOGY.

Microscopical Appearance.

This organism is fairly pleomorplic, and varies in length from $4 \mu$ to $25 \mu$, with an average length of 8 to $9 \mu$. Its thickness varies with the staining method employed, but the Japanese workers are of the opinion that it is probably about $0.25 \mu$. The ends are sharp and pointed, and are in most cases hooked, not uncommonly both ends being bent to the same side in the form of a letter $\mathrm{C}$, or one end is bent in an opposite direction to the other, giving the parasite an S-shaped form. The spirochaete, unlike Treponema pallidum, shows irregular undulations usually composed of 2 to 3 large or 4 to 5 smaller waves. This is not always the case, Martin and Pettit pointing out that occasionally one comes across forms in which the waves are more numerous and more regular, the parasite approaching more the form of T. pallidum. In the blood the spirochaete conforms to the typical form, except in those severe infections where it is very numerous, and then one meets with parasites bent in the form of a ring or twined one about another. On the other hand, the forms met with in the liver vary much in shape and length. One sees straight forms, others bent at one end only, giving the parasite the appearance of a note of interrogation, and again others showing round or oblong granules, 3 to 4 in number, staining a deep purple with Giemsa. Still larger granules may sometimes be observed projecting from the body of the spirochaete-the so-called "lateral bud" of the spirochaete already described in the case of other varieties - the significance of which is not apparent. Degenerative forms are also met with which are thick, devoid of waves, and blunt at the ends. Flagella were not described by the Japanese, but Martin and Pettit and Vaudremer in a recent publication describe flagella, which they have been able to demonstrate by Löffler's and Van Ermengem's staining methods. These are terminally placed, and vary in number and length. Further, they have been able to show that the flagellum ends in a small circular knob, the significance of which has yet to be elucidated.

Staining Methods.-Unstained in a hanging drop preparation, the spirochaete is invisible with the ordinary microscope except when very numerous, and even then its presence is detected only with the greatest difficulty.

Dark-ground Illumination.-By this means the spiro. chaete can be readily studied. It is not nearly so refractile as $T$. pallidum, and its movements are much more sluggish. As a rule it remains motionless, or is simply carried across the field by the currents set up between the slide and cover-slip. It is, however, capable of lashing movements of the extremities, the centre portion of the parasite remaining rigid, or it may show twisting worm. like movements.

Dried Sinears.-Smears of blood, tissues, or urine sediment can be readily stained by Geimsa, Leishman, Tribondeau, or a rapid silver impregnation method such as Fontana. With Giemsa, after a preliminary fixation with methyl alcohol, absolute alcohol, or osmic acid, the preparation is stained for two hours with a mixture of 20 drops of stain in $10 \mathrm{c.cm}$. of water. Generally speaking, when the leucocytic granules are deeply stained; the spirochaete will be found to be stained. With Leishman, after the preliminary fixation for one minute with undiluted stain;, the diluted stain is allowed to act for thirty minutes. This gives quite satisfactory results, and though not deeply stained the spirochaete is readily visible. Coloured by these methods, the spirochaete has a pinkish-puiple tint. Burri's Indian ink method and similar processes give us a rapid and satisfactory means of demonstrating the spirochaete in smear preparations, but perhaps the most satisfactory of all is that of Fontana, which consists of staining the preparation with an ammoniated silver nitrate solution after a preliminary mordancing with 5 per cent. aqueous solution of tannic acid.

Staining of Sections.-The most satisfactory staining process for sections will be found to be the older Levaditi method.

Staining of Flagella.-For this purpose the methods of Löffler and Van Ermengem both give satisfactory results. The following are the directions given by Martin, Pettit, and Vaudremer:

(a) Löfler. Fix in ether-alcohol. Cover the preparation with Löffler's fuchsia ink and heat gently, stopping the heating as soon as the preparation commences to steam. Wash in distilled water, and then three times with absolute alcohol. Stain with alkaline aniline gentian violet, warming gently. Wash in distilled water and drv.

(b) Van Ermengem. Follow the classical technique, but in place of Ziehl's carbol fuchsin stain the preparation with alkaline aniline gentian violet, diluted so as to obtain a background not too deeply stained.

\section{Cultivation Experiments.}

The first successful attempts to cultivate the spirochaete were those of the Japanese Ito and Matsuzaki. 
Starting from the infected guinea-pig, the spirochaete was obtained in pure culture by the method of Noguchi, guinea. pig lidney replacing that of the rabbit usually employed. The cultures were covered by a layer of liquid paraffin. The best results were obtained at a temperature of $22^{\circ}$ to $25^{\circ} \mathrm{C}$. They noticed that growth commenced in from three to seven days, or rarely after a delay of as much as two weeks, that the first generation lived for three to six weeks, and that the lives of the succeeding generations were rather shorter. Since then they have succeeded in growing the organism on various different media, solid and liquid-blood agar and gelatin, human serum, diluted ox serum and ascitic fluid. Martin and Pettit in repeating this work have been unable to obtain cultures on solid media, but, however, have been successful with various liquid media. The most satisfactory they found to be diluted rabbit serum ( 1 in 5 of normal saline), and diluted ox serum ( 1 in 9 of normal saline), without the addition of pieces of tissue, but merely covered with a layer of liquid paraffin. The organism grows well at a temperature of between $25^{\circ}$ and $32^{\circ} \mathrm{C}$, refusing to grow at $37^{\circ} \mathrm{C}$. or only after acclimatization. The cultures are inoculated with the heart blood or emulsion of liver of a jaundiced guinea-pig which has been preferably killed and not allowed to die of the disease. The cultures remain clear, any cloudiness or turbidity being an indication of contamination and of failure because the spirochaete refuses to grow, or only shows feeble growth in the presence of other organisms. The cultures are without odour and ascitic fluid remains uncoagulated. In culture the spirochaete is evenly distributed throughout the media, and is shorter and more active than when seen in the tissues. Occasionally one sees several spirochaetes intertwined together in the form of a rosette, and here and there individuals of exceptional length. As the culture becomes older the organism becomes less active, and degeneration forms make their appearance. Subcultivation should be practised when growth is at its height, that is, when spirochaetes are numerous and active. The cultures are capable of reproducing the disease in the guinea-pig, and their virulence is maintained up to the twenty-second day.

\section{Mode of Spread of the Disease.}

In their first communication the Japanese authors expressed the opinion that infection occurred through the skin or by the mouth. As was shown by them, the spirochaete is excreted chiefly by way of the urine, which provides a ready means for the dissemination of the virus. They had noticed, also, that epidemics of jaundice occurring in mines were confined to "wet" mines, and that if in a mine the cases came from one particular portion, that portion of the mine was invariably a flooded one. The animal experiments performed by them showed that the guinea-pig could be readily infected by way of the mouth, or by simply applying the infectious material to the shaved skin, abraded or intact-five minutes' contact being sufficient for infection to have taken place. Knowing these facts it seemed probable that in these epidemics, in the mines at any rate, the water having been contaminated by urine the spirochaete gained entrance to its new host via the skin or by the mouth. This was further borne out by the fact that when the flooded portions of the mine were pumped dry the incidence greatly decreased. In the communication of Stokes, Ryle and Tytler attention is drawn to the fact that the cases of jaundice occurring in this sector of the line came almost exclusively from one or two portions of the front line trench, and that as soon as the units were moved out of these particular trenches they ceased to have cases of jaundice, and in a similar. manner fresh units moving into them, who had had no cases up to that tine, almost inmediately commenced to develop them. These portions of trench when compared with the rest of the line were distinguished from the remainder by always being in a very wet condition, it being impossible to drain them properly. In their first paper the Japanese discussed the possibility of biting insects, such as the flea or mosquito, playing a part in the spread of the disease from man to man, but concluded that the smallness of the numbers of the spirochaetes in the peripheral circulation made it very doubtful. Stokes also undertook experiments with a view to finding out if the body louse, so common amongst the troops, could be in criminated. When one considers, however, how general the distribution of the louse is, and how localized the areas from which cases of jaundice come, this does not seem probable. His experiments proved negative. In a resent communication the Japanese state that they have been able to show the presence of the spirochaete in 38 per cent. of the field rats coming from areas in which jaundice was epidemic, and they suggest that the infection may be conveyed by the rats' urine directly or indirectly. Stokes has been able to confirm this finding, six out of fifteen rats caught in these areas in which jaundice was endemic having been shown to contain the spirochaete in the kidney capable of producing the disease in the guinea-pig. It would appear, therefore, that the rat acts as a reservoir for the infective agent, spreading the disease by means of its urine directly or indirectly, and that infection is further spread by the patient's urine and faeces.

\section{Immunity.}

The Japanese in their first paper pointed out that the blood of convalescent pationts contained protective sub. stances capable of neutralizing the virus in vitro, and of protecting the guinea-pig against infection. This substance is first demonstrable in the blood serum after the tenth day of illness, but, as a rule, is not found before the filteenth to the twentieth day. 'This immune substance persists in the blood for a long time, the Japanese authors quoting two cases in which it was detected at the end of five and a half years. It is specific, and is not present in the serum of healthy persons, nor in the serum from cases of jaundice of other origin.

The immune substances can be demonstrated by the re. action of Pfeiffer, the results of the experiment being confirmed by the subsequent condition of the guinea-pigs, the control animal developing jaundice and dying, while the other which received the virus and the patient's serum remains unaffected. They also showed that this substance was endowed with curative properties, the diseased guinea. pig being cured by an injection of the patient's serum if it was administered before the onset of jaundice. These facts have been confirmed by the French and by Stokes, the latter having shown that even after the appearance of jaundice the guinea pig can be cured, provided the serum is injected before the collapsed stage is reached. In view of these facts, the Japanesc. have prepared an antiserum by immunizing a llorse, and report encouraging results from the employment of this serum therapeutically. The French also are preparing an antiserum, but so far have published no results of its application in the disease.

Attempts have also been made to demonstrate immune bodies in the patient's serum by means of the reaction of the fixation of complement. As antigen an emulsion of liver rich in spirochaetes was employed. Stokes reports negative results with this reaction, and, while Martin and Pettit state that it was positive in the five cases in which it was tried by them, they at the same time admit that a strongly syphilitic serum gave a positive result also.

The serum of the patient, according to Garnier and Reilly, does not agglutinate the spirochaetes, whereas the Pasteur Institute serum agglutinates them readily, the spirochaetes losing their nobility and running together into clumps.

VII. Bacteriological Diagnosis.

Direct Examination of the Blood.

Owing to the shortness of the period during which the organism is to be found in the circulation and the smallness of its numbers when present therein, the direct examination of blood smears for the spirochaete is of little value as a practical method of diagnosis. However, in the early stages of disease (up to the seventh day) it is sometimes possible to demonstrate the spirochaete in this manner, and, seeing that it requires little time or trouble, it is worthy of trial. The blood may be examined by means of the ultra-microscope; blood smears may bo stained by Giemsa, Leishman, and Fontana, or preparations made with Burri's Indian ink method.

\section{Animal Inoculation.}

The reproduction of the disease in the guinca-pig by the injection of the patient's blood or urine is undoubtedly the most satisfactory and convincing diagnostic test we at present possess, but unfortunately, owing to the fact that it is only in the early stages of the disease that the blood 
is infective and that the infectivity of the urine is a very variable quantity, this method of diagnosis as a practical measure has its limitations. In the early days of the disease, up to the serenth or even ninth day, one, or preferably two, guinea-pigs should be inoculated intraperitoneally with 3 to $5 \mathrm{c.cm}$. of the patient's blood. Injection of larger quantities of blood is of itself sufficient frequently to kill the guinea-pig. In a positive case, after an incubation period of from six to twelve days, the animal develops the disease and dies, showing the characteristic changes already described. Similarly, in the early days of the disease the injection of the urine into the guinea-pig should be done, and even after the blood has ceased to be infective and the case is well advanced, it is perhaps worthy of trial, because, as shown by Garnier and Reilly, positive results may be obtained as late as the twentyeighth day. These workers inject the centrifugalized deposit from 40 to $60 \mathrm{c.cm}$. (occasionally as much as 150 to $250 \mathrm{c.cm}$.) of recently passed urine, suspended in $5 \mathrm{c.cm}$. normal saline. Naturally all precautions as regards sterility must be observed in the collection and centrifugalization of the urine.

Examination of the Urine for Spirochaetes.

As pointed out by the Japanese, the spirochaete is eliminated chiefly by way of the kidney, and from the ninth day onwards can be demonstrated microscopically in the urine. At first it appears in the urine in small numbers only, the number gradually increasing to a maximum reached about the thirteenth to fifteenth day of disease, to diminish again and finally disappear from the urine about the fifth or beginning of the sixth week of illness. Should, therefore, a case of jaundice present itself too late in the disease to make the injection of the guinea-pig with the blood of no use, and should the injection of a guinea-pig with the urine have proved negative, the demonstration of the spirochaete in the urine gives us valuable information as to the cause of the jaundice. The procedure is simple and is as follows: The urine is collected in a sterile vessel and $50 \mathrm{c.cm}$. or so centrifuged. The deposit so obtained is washed with distilled sterile water and recentrifuged and smears made with the final deposit. Preparations can be made by the Indian ink method, Harrison's collargol method, or with a 2 per cent. aqueous solution of Congo red, treating the smear so obtained with 1 per cent. $\mathrm{HCl}$ in alcohol, as recommended by Benians. These methods have the advantages of rapidity and simplicity, but in our opinion the best is the staining of dried smears by the method of Fontana. Should, therefore, the urine of a case of jaundice, examined in this manner towards the end of the second or beginning of the third week, show the presence of numerous spirochaetes having the morphological characters of the Spirochaeta icterohaemorrhagiae already described, and should the case have been proved negative for the enteric group by blood culture, examination of stools and urine for bacilli or by agglutination, there is little doubt that the case in question is one of spirochaetosis. It must be borne in mind, however, that it is not sufficient to examine the urine on one occasion only, but several examinations at intervals of two to three days may be necessary before the spirochaete is found. Even then, as pointed out by Stokes, we may fail to find the spirochaete because it is to be expected that in mild cases the numbers excreted will be small, and the period during which they are to be found in the urine transient. It cannot be claimed, however, that this method of diagnosis has the same value as the production of jaundice in the guinea-pig as there are certain obvious sources of error. These are the limitation of the microscope when used alone to determine the species of micro-organism with which one is dealing and the presence of other bodies in the preparation resembling spirochaetes liable to mislead an inexperienced observer. The latter error should not be made by a skilled worker, and though the examination by us of control urines from cases of scarlet fever, measles, lobar pneumonia, typhoid and paratyphoid fever have occasionally revealed the presence of spirochaetes, this has been of rare occurrence, and in no case did these spirochaetes or spirilla bear any morphological resemblance to the Spirochaeta icterohaemorrhagiae. We have, therefore, concluded that in a case of jaundice the clinical symptoms of which point to spiroclraetosis, which has been proved negative to the enteric group, and in the urine of which spirochaetes with the morphology of Spirochaeta icterohaemorrhagiae have been found, one is in possession of a chain of evidence warranting the diagnosis of spirochaetal jaundice.

\section{Immunity Reactions.}

1. Reaction of Neutralization.-This reaction, already referred to under the heading of immunity, can be made use of in diagnosis. It suffices to mix a toxic dose of virus (liver emulsion) with 1 to $2 \mathrm{c.cm}$. of the serum from the case in question and to inject it into a guinea-pig intraperitoneally. The control animal receives the virus alone. If the case is one of spirochaetosis, the guinea-pig remains unaffected, the control animal dying with the characteristic post-mortem changes; on the other hand, if the case were not one of spirochaetosis, both animals would develop jaundice.

2. Fixation of Complement.-It would not appear that in our present state of knowledge, this reaction would be of much service in diagnosis. Martin and Pettit report positive results, however, in the five cases in which it was tried by them, but the value of these results was somewhat detracted from by the fact that a strongly syphilitic serum gave a positive result as well with their antigen.

\section{CONCLUSION.}

It would seem to be proved that there is in the armies in France a type of infective jaundice which is the same in clinical and pathological features as that described by the Japanese workers, and that this disease is caused by the Spirochaeta icterohaemorrhagiae. And there is also undoubted proof that this same spirochaete may cause a similar train of symptoms without the appearance of jaundice.

A complete bibliography is appended, and to the authors of the various publications we acknowledge our debt.

Benians: Relief Staining foriography.

. Relief Staining for Bacteria and Spirochaetes. BRITIsH UDAL JodRNAL, November 25th, 1916, p. 722 .

Gelbsule der anstechenden Gelbsucht. Berl. klin. Woch. vol. liii, February 2lst, 1916.

Cockayne: Catarrhal Jaundice, Sporadic and Epidemic (with full Historical Bibliography). Quarterly Journ. of Med., vol. vi, No. 21 , Costa, $1912, \mathrm{p}$. 1 .

Costa and Troisier: Mort du lapin et survie du cobaye dans la Spirochétose ictérohémorrhagique expérimentale, Compt. Rend. de la Societe de Biologie, vol. Ixxx, January 6th, 1917, p. 27. Réaction spirochétose ictérohémorrhagique, Ibid., vol. 1xxx, January 6th, 1917 p. 29.

Dawson and Hume: Jaundice of Infective Origin. Quarterly p. 90 .

Garnier: La transmission au cobaye de l'ictère infectieux primitif. C.R. de la Soc. de Biologie, vol. lxxix, November 4th. 1916.

Garnier and Reilly: L'ictère infectieux à spirochètes. Société Médicale des Hôpitaux, December 22nd, 1916. La recherche du spirochète ictérigène dans l'urine de l'homme et du cobaye, $C$. R. de la Soc. de Biolngie, vol. 1xxx, January $6 \mathrm{th}, 1917, \mathrm{p} .38$. Action de la bile sur la virulence de Spirochaeta icterohaemorrhagiae, Ibid., vol. Ixxx. January 6 th, 1917, p. 4. La recherche des substances immunisante chez les convalescents de spirochétose ictérigène, Ibid., vol. 1xxx, January 19th, 1917. La spirochétose ictérigène, Paris Médicale, No. 9, March 3rd, 1917, p. 176

Hübener and Reiter : Beiträge zur Ættiologie der Weilschen Krankheit, Deut. med. Woch., vol. xli, October 21st. 1915, p. 1875. Zur Etiologie der Weeilschen Krankheit, Ibid.. vol. xlii, January 6th, 1916 , p. 1; and February 3rd, 1916, p. 131. Die Atiologie der Weilschen Inada, Ido, Hoki, Kaneko, and Ito: The Juary 14th, 1916, p. 171: Inada, Ido, Hoki, Kaneko, and Ito: The Etiology, Mode of Infection, March lst, 1916, p. 377.

Ito and Matsul p. 377 .

haemorrhagiae (Inaid The Pure Cultivation of Spirochaeta ictero 1916. p. 557.

Martin and Pettit. Préparation microscopiques et anatomiques relatives à la spirochétose ictérohém et de pièces de la Soc. de Biologie, vol. Ixxix, July 22nd, 1916, p. 659 que, $\boldsymbol{C}$. $\boldsymbol{R}$. chétose ictérohémorrhagique, Bull. Méd., July 28th, 1916. Trois cas de spirochétose ictérohémorrhagique en France, Bull. de l'Acad. de Méd., vol. Ixxvi, October 10th, 1916, p. 247. La spirochétose ictérohémorrhagique en France, La Presse Médicale, No. 69, December 14th. 1916.

Martin, Pettit, and Vaudremer: Coloration du spirochète de l'ictère hémorrinagique par les méthodes de Löffler et de Van Ermengem; Frésence de cils. C. R. de la Soc, de Biologie, vol. lxxix, Stokes 2nd, 1916, p. 1053.

Stokes and Ryle: A Short Note on Weil's Disease as it has occurred in the Army in Flanders. British Medical Jodrnal, September 23rd, S16, p. 413.

Stokes, Ryle, and Tytler: Weil's Disease (Spirochaetosis IcteroNo. 4874. January 27 the British Army in Flanders. Lancet, vol. cxcii o. 4874, January 27th, 1917, p. 142

Uhlenhuth and Fromme: Experimentelle Untersuchungen über die ber 3lst, 1915, p 1202 Wrankheit, Med. Klinik (Vienna), vol. xi, Octodie sogenannte. Weilschen Krankheit, Ibid., vol, $x i$. November über 1915, p. 1264. Experimentelle Grundle, Ibid., vol. xi, November 14th, lung der Weilschen Krankheit, Ibid., vol. xi, November 21st, 1915 p. 1296: and December 12th, 1915, p.1375. Zur Æitiologie der sogent, 1915, Weilschen Krankheit, Beri. klin. Woch., vol. liii, March 13th, 1916,
p. 269 . 